\title{
Natural durability and
} dimensional stability of white mulberry (Morus alba L.) for Middle
Eastern lutes

\section{Durabilidad natural y estabilidad dimensional de mora blanca (Morus alba L.) para laúdes del Medio Oriente}

\author{
Aida Se Golpayegani23*, Marie-France Thevenon², Iris Bremaud', Kambiz Pourtahmasi and Joseph Gril'
}

1 Université Montpellier 2. Laboratoire de Mécanique et Génie Civil (LMGC), Montpellier, France. iris.bremaud@umontpellier.fr; joseph.gril@umontpellier.fr

*Corresponding author. aida.golpayegani@gmail.com

\author{
2 CIRAD. Wood, Energy, Bio-products. Research Unit \\ Biomass. Montpellier, France. marie-France.theve- \\ non(a)cirad.fr
}

3 University of Tehran. Faculty of Natural Resources. Department of Wood and Paper Science and Technology. Iran. pourtahmasi@ut.ac.ir

\begin{abstract}
Instrument makers prefer wood species which not only have excellent acoustical properties, but also tend to keep their natural state when going through preparations and pretreatments. In this study long time water soaking, a common protocol among Iranian lute makers, was used to investigate the natural durability and dimensional stability of White mulberry (Morus alba L.). The wood of white mulberry, which is the only source for making Iranian lutes for more than a century, was examined for its natural resistance towards fungi and termites. Samples were also studied for their dimensional change during four months of water soaking. White mulberry, whether leached or unleached, showed to be a very resistant species towards both termites and fungi. Gradual removal of the extractives during water immersion resulted in an increase in partial shrinkage. It was concluded that water leaching, though not affecting the natural durability, tends to reduce the dimensional stability of white mulberry.
\end{abstract}

KEYwORDs: dimensional stability, musical instruments, natural durability, Reticulitermes flavipes (ex.santonensis), water leaching, white mulberry (Morus alba L.).

\section{RESUMEN}

Los fabricantes de instrumentos musicales (lauderos) prefieren madera de especies que no solo tengan excelentes propiedades acústicas, sino que además tiendan a mantener su estado natural durante su fabricación y pretratamientos. En este estudio se hicieron pruebas de inmersión en agua, un protocolo común entre los lauderos iraníes, para determinar la durabilidad natural y estabilidad dimensional de la madera de mora blanca (Morus alba L.). La madera de esta especie, la cual es la única que ha utilizado para la fabricación de los laúdes iraníes por más de un siglo, fue probada para determinar su resistencia natural al ataque de hongos y termitas. Los especímenes fueron estudiados para detectar cambios en sus dimensiones durante cuatro meses de inmersión en agua. La madera en estudio, lixiviada o no, mostró muy alta resistencia tanto al ataque de hongos como al de termitas. La remoción gradual de extractivos durante la inmersión resultó en un incremento en la contracción parcial. Se concluyó que, aun cuando la lixiviación en agua no afecta la durabilidad natural, tiende a reducir la estabilidad dimensional de la madera de mora blanca.

Palabras clave: estabilidad dimensional, instrumentos musicales, durabilidad natural, Reticulitermes flavipes (ex.santonensis), filtración de agua, morera blanca (Morus alba L.). 


\section{INTRODUCTION}

Wood has been the most commonly chosen material for making musical instruments. From ancient flutes and drums to the sophisticated violins and pianos, this material has always played a significant role in both performance and aesthetic features of the instrument. Beside visual aesthetics, the quality of any musical instrument is strongly related to three factors: i) its acoustical characteristics, ii) its stability and iii) its durability. While acoustical features can include a variety of factors and indexes (i.e. damping or $\tan \delta$, specific modulus of elasticity $(E / \rho)$, sound speed, radiation), wood dimensional stability is signified by changes of three orthotropic dimensions ( $\mathrm{L}, \mathrm{R}, \mathrm{T}$ as in longitudinal, radial and tangential) of a given specimen under different moisture conditions.

Although wood can be kept under different humidity conditions, the equilibrium moisture content (EMC) tolerance for musical instruments is often small. Besides, natural durability goes hand in hand with the possibility of a wooden instrument being made without any chemical treatment and maintained for several centuries without risking the attack of damaging microorganisms or insects.

White mulberry wood is used for making traditional long necked lutes in Middle East for centuries, resulting in creating some spectacular Tars and Setars. However, this species' physical characteristics remained scientifically unknown until very recently (Se Golpayegani et al. 2012). Both dimensional stability and natural durability of Iranian white mulberry, however, are yet to be examined in relation with instrumental use of this species.

Dimensional stability of wood comes to attention whenever the use of the material is in question (Rowell and Young, 1980; Rowell and Banks, 1985; Glass and Zelinka, 2010). For any long time use, it is almost essential that wood either holds to its original dimensions, or to bear the least possible alteration when facing humidity changes in the surrounding. Also, the stability of mechanical properties may often be associated with the dimensional stability. Different chemical and physical treatments were used to improve the dimensional stability of various species (Militz, 1993; Ohmae, Norimoto and Minato, 1997; Sakai, Matsunaga, Minao and Nakatsubo, 1999; Gunduz, Korkut and Korkut, 2008; Li, Cai, Mou, Wu and Liu, 2011). Moreover, mechanical factors can vary from instrument to instrument; if low damping and density are required for guitar and violin top plates, wind instruments need a high density material. However, a strong dimensional stability is mandatory for most musically important species (Bucur, 2006; Wegst, 2006 and 2008).

Natural durability of heartwood depends on different factors: presence or absence of extractives, local anatomical defaults and humidity (Highly, 1995; Scheffer and Morell, 1998; Evans, Flate and Alfredsen, 2008). The presence of extractives is often correlated with high natural durability Windeisen, Wegener and Lesnino (2002); Haupt et al., 2003).

Natural durability of white mulberry against basidiomycetes (Morus alba) has been the subject of a few contradictory studies. The durability of European, Asian and Australian white mulberries varied from moderately durable to non-resistant (Tewary 1979 cited in Scheffer and Morell 1998); while white mulberry from India was found to be very resistant towards fungi (Zamir, 2008). Also, Red mulberry (Morus rubra) and Osage orange (Maclura pomifera), both Moraceae, are listed to be very resistant (Clausen, 2010).

As part of wood preparation for instrument making, artisans do some pretreatments involving water, either to improve instrument final performance or to make the wood more workable (Se Golpayegani, Brémaud, Grill, Thévenon and Pourtahmasi et al., 2015). Studying natural durability of untreated and leached white mulberry would shed a light on the consequence of water treatment on the resistance of wood against damaging biological attacks. Furthermore, some investigation on the dimensional stability of water soaked wood would be undoubtedly helpful towards better comprehension of the instrumental use of this species. 


\section{OBJECTIVES}

\section{This study was done in order to:}

1. Investigate the effect of water soaking as a traditional pretreatment on the dimensional stability of white mulberry.

2. Study the behaviour of wood towards degrading microorganisms after water treatment.

3. Interpret the results in relation with the instrumental use of the species.

\section{MATERIALS AND METHODS}

\section{Materials}

One white mulberry tree was selected by a professional lute maker in Iran. The tree was cut from a forest near Karaj province in Iran. At the time of the cutting (November 2008, when the growing season was over), the minimum and maximum temperature were $-5{ }^{\circ} \mathrm{C}$ and $+26{ }^{\circ} \mathrm{C}$ with an average $\mathrm{RH}$ of $55 \%$.

Tree was trimmed from its branches at $1.30 \mathrm{~m}$ height, air dried for one month and then cut to eight portable rods $\left(50 \mathrm{~cm}^{3} \times 5 \mathrm{~cm}^{3} \times 5 \mathrm{~cm}^{3} \mathrm{~L} \times \mathrm{R} \times \mathrm{T}\right)$ before being shipped to the CIRAD laboratory in France.

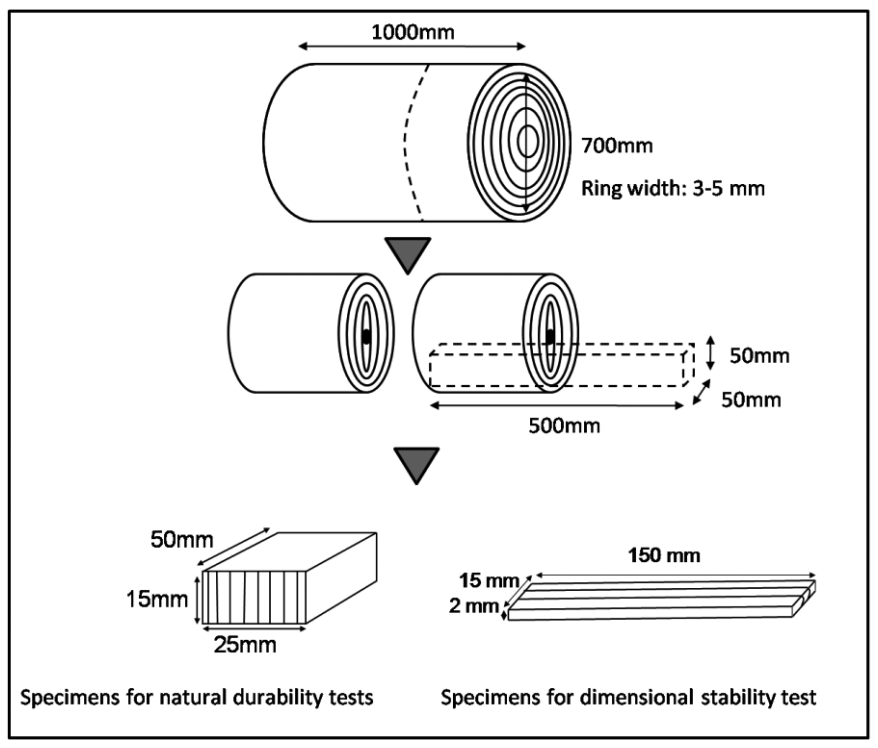

FIGURE 1. Specimen preparation for tests.
Rods were kiln dried for 2 weeks in a commercial Cathlid® Kiln $\left(12{ }^{\circ} \mathrm{C}\right.$ to $35^{\circ} \mathrm{C}$, increasing gradually and used simultaneously with a humidifier) before being moved to a climatic chamber to be stabilized at $20^{\circ} \mathrm{C} \pm 2$ ${ }^{\circ} \mathrm{C}$ and $65 \% \pm 5 \% \mathrm{RH}$ for 3 weeks. At the end of this process, the material was cut to the test specimens (Fig. 1). Only heartwood was used for sampling.

\section{Specimens for dimensional stability}

Eighteen samples from mid-heartwood were cut to the following dimensions $\left(2 \mathrm{~mm}^{3} \times 15 \mathrm{~mm}^{3} \times 150 \mathrm{~mm}^{3}\right.$ $\mathrm{L} \times \mathrm{R} \times \mathrm{T})$. Great care was taken for orthotropic directions to correspond closely to the cut samples and to avoid intermediary ones (Fig. 1).

\section{Specimens for natural durability tests}

Specimens $\left(50 \mathrm{~mm}^{3} \pm 0.5 \mathrm{~mm}^{3} \times 25 \mathrm{~mm}^{3} \pm 0.5 \mathrm{~mm}^{3} \times 15\right.$ $\left.\mathrm{mm}^{3} \pm 0.5 \mathrm{~mm}^{3} \mathrm{~L} \times \mathrm{R} \times \mathrm{T}\right)$ were cut from original rods, from which 120 were selected for testing the durability against termites and fungi. The exact volume of each specimen was calculated.

The conditioning of two weeks in $20{ }^{\circ} \mathrm{C} \pm 2{ }^{\circ} \mathrm{C}$ and $65 \% \pm 5 \% \mathrm{RH}$ was applied to all specimens as well as controls, prior to any biological test.

\section{METHODS}

\section{Dimensional stability}

Samples were initially dried at $60{ }^{\circ} \mathrm{C}$ for $48 \mathrm{~h}$ and then kept in climatic chamber for 3 weeks $\left(20^{\circ} \mathrm{C} \pm 2{ }^{\circ} \mathrm{C}\right.$ and $65 \% \pm 5 \% \mathrm{RH})$. Then they were separated to 5 groups of 12 , where each was immersed in water at ambient temperature for various amounts of times $(0$ months - 4 months, where 0 stands for controls which were only subjected to drying and stabilizations). The partial drying and stabilization were repeated at the end of treatments $\left(60^{\circ} \mathrm{C}\right.$ for $48 \mathrm{~h}$ then 3 weeks at $20{ }^{\circ} \mathrm{C} \pm 2{ }^{\circ} \mathrm{C}$ and $\left.65 \% \pm 5 \% \mathrm{RH}\right)$. A final thorough drying $\left(103{ }^{\circ} \mathrm{C}\right.$ for $\left.48 \mathrm{~h}\right)$ afterwards was done to insure samples had reached anhydrous state. As these samples also served to determine the effect of traditional pretreatments on the acoustical properties of the 
species, further details on this protocol are detailed in Se Golpayegani et al. (2015).

The samples dimensions ( $\mathrm{R}, \mathrm{T}$, and $\mathrm{L}$ axis) and their weight were noted before and after the treatment, and at three different stages of drying $\left(60^{\circ} \mathrm{C} / 48 \mathrm{~h}, 103^{\circ} \mathrm{C} / 48 \mathrm{~h}\right.$, $27{ }^{\circ} \mathrm{C} \pm 2{ }^{\circ} \mathrm{C}$ and $75 \% \pm 5 \% \mathrm{RH} / 3$ weeks, as a mild rehumidification) and were compared for their partial shrinkage $(\Delta \mathrm{V})$ and the effect of water immersion.

\section{Natural durability}

Investigation of natural durability of solid heartwood against fungi was done according to guidelines of XP CEN/TS 15083-1 (2006), except that in each culture flask one Morus and one control specimen of the same dimension were incubated together (Pinus sylvestris sapwood for brown rot, Fagus sylvatica for white rot). Natural durability towards termites was done according to the guidelines of EN117 (2013). As water immersion is one of the common pretreatments of white mulberry for Tar (Se Golpayegani et al., 2015), half of the specimens were leached according to EN84 (1997) prior to biological tests to understand the effect of water on the long time durability of wood.

\section{TEST PROCESSES}

\section{Fungi}

The complete description and conditioning for the fungi used in this study can be seen in table 1. Pycnoporus san- guineus and Antrodia sp., two aggressive tropical fungi were added as discriminators and as the representatives of the original region.

For each fungus, 10 specimens of Scot pine sapwood (Pinus sylvestris L.) and beech (Fagus silvatica L.) were virulence controls for brown rot and for white rot respectively. The resistance was determined by the mass loss (on anhydrous basis) of the samples (after 16 weeks of fungal exposure) expressed as mean mass loss as well as median mass loss.

The natural durability classification was established according to table 2 .

\section{Termites}

The durability against termites was evaluated for 10 unleached and 10 leached specimens. Virulence control was also performed using 6 specimens of Scots pine sapwood (Pinus sylvestris). The termites used were Reticulitermes flavipes (ex. santonensis). After 8 weeks of exposure to termites, visual rating of the sample and weight loss (on anhydrous basis, as for the fungal decay), were determined.

\section{RESULTS}

\section{Dimensional stability}

Figure 2 illustrates the relation between density and the partial shrinkage (between air dried and $60{ }^{\circ} \mathrm{C}$ ) of all

TABLE 1. Fungal strains and climatic conditions for tests against basidiomycetes.

\begin{tabular}{|c|c|c|c|c|}
\hline \multirow[t]{2}{*}{ Fungi name } & \multirow[t]{2}{*}{ Type } & \multicolumn{2}{|c|}{ Number of specimens } & \multirow[t]{2}{*}{ Condition for the test } \\
\hline & & Leached & Unleached & \\
\hline Coriolus versicolor & White Rot/ strain CTB 863-A & 30 & 30 & $(22 \pm 2)^{\circ} \mathrm{C}$ \\
\hline Coniophora puteana & Brown Rot/ strain BAM Ebw.15 & 30 & 30 & $(70 \pm 5) \% \mathrm{RH}$ \\
\hline Gloeophyllum trabeum & Brown Rot/ strain BAM Ebw.109 & 10 & 10 & \\
\hline Poria placenta & Brown Rot/ strain PRL 280 & 10 & 10 & \\
\hline Pycnoporus sanguineus & White Rot/ strain CTFT 270 & 10 & 10 & $(27 \pm 1)^{\circ} \mathrm{C}$ \\
\hline Antrodia $s p$ & Brown Rot/ strain CTFT 57 A & 10 & 10 & $\begin{array}{c}>75 \% \mathrm{RH} \\
\text { (Tropical conditions) }\end{array}$ \\
\hline
\end{tabular}


TABLE 2. Natural durability classification according to XP Cen/ TS 15083-1(2006).

\begin{tabular}{ccc}
\hline Durability class & Description & Median mass loss (\%) \\
\hline 1 & Very durable & $5 \%$ \\
2 & Durable & $>5 \%$ to $10 \%$ \\
3 & Moderately durable & $>10 \%$ to $15 \%$ \\
4 & Slightly durable & $>15 \%$ to $30 \%$ \\
5 & Non durable & $>30 \%$ \\
\hline
\end{tabular}

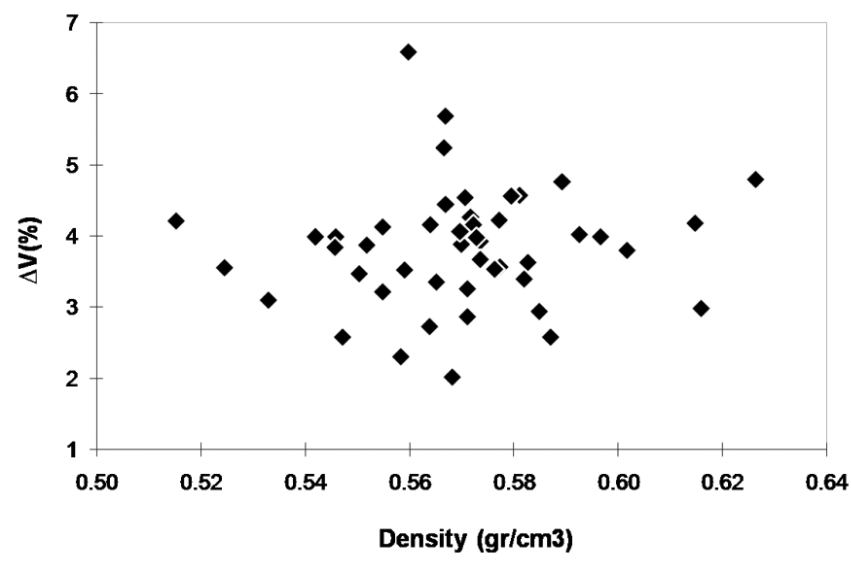

Figure 2. Relationship between change in volume $\Delta \mathrm{V} \%$ (between air dried and $60{ }^{\circ} \mathrm{C} / 48 \mathrm{~h}$ ) and density (measured at $60{ }^{\circ} \mathrm{C} / 48 \mathrm{~h}$ ) for 60 samples before submitting to treatment.

samples chosen for dimensional stability tests before any treatment is applied.

Partial shrinkage for untreated samples was $\approx 3.73 \%$ $\pm 1.15 \%$ for an average $\rho \approx 0.55 \mathrm{~g} / \mathrm{cm}^{3} \pm 0.04 \mathrm{~g} / \mathrm{cm}^{3}$. The noticeable broad variation is due to the large changes in the comparatively small $\mathrm{T}$ dimension (which was necessary for the vibrational tests; Se Golpayegani et al., 2015). The tangential dimension of $2 \mathrm{~mm}$ is very susceptible to change of humidity and the changes are very hard to record. Evidence to that fact is $\Delta \mathrm{LR} \approx 1.78 \% \pm 031 \%$ and $\Delta \mathrm{T} \approx 2.04 \% \pm 1.01 \%$.

Specimens' dimensions after water soaking remained stable after going through three weeks of mild conditio-

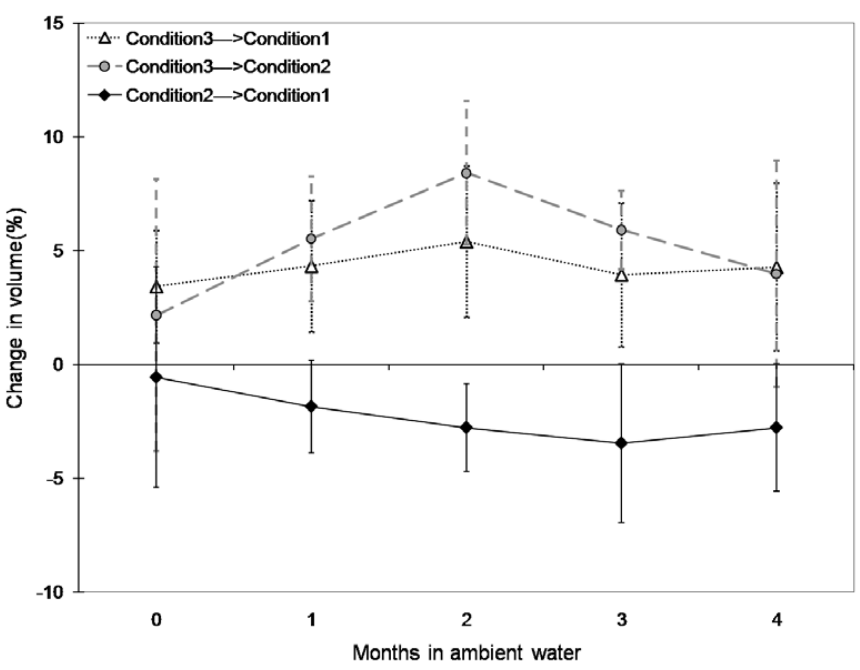

FIGURE 3. Change in volume after treatment between three conditions (Condition 1: $60{ }^{\circ} \mathrm{C} / 48 \mathrm{~h}$, Condition 2: $103{ }^{\circ} \mathrm{C} / 48$ h, Condition $3: 27^{\circ} \mathrm{C} / 75 \% \mathrm{RH} / 3$ weeks). 0 stands for controls. Calculations in each case: ((Volume at later condition - Volume at earlier condition) / Volume at earlier condition) $\%$.

ning (average $\Delta \mathrm{V} \approx 4.33 \%, 5.41 \%, 3.95 \%$ and $4.29 \%$ for 1 to 4 months water immersion, compared to $\Delta \mathrm{V} \approx 3.43 \%$ for controls) (Fig. 3). These values are also significantly lower if the effect of $\Delta \mathrm{T}$ is subtracted (average $\Delta \mathrm{RL} \approx$ $2.71 \% \pm 0.83$ for all treated samples), though the uniformity of changes versus treatment months remains the same.

Water treatment seems to play a role in dimensional stability when samples were dried to the complete anhydrous state (Fig. 3). $\Delta \mathrm{V}$ is gradually decreasing along with the months, reaching its greatest value at $3^{\text {rd }}$ month $\approx$ $-3.46 \%$. Comparing the anhydrous and conditioned states $\left(103{ }^{\circ} \mathrm{C}\right.$ and $\left.27^{\circ} \mathrm{C} / 75 \% \mathrm{RH}\right)$, a roughly mirrored image of the last graph is revealed (Fig. 3). In both cases the longer treatment times contribute to the instability of dimensions.

Water is a well known solvent for extractives and is used both in laboratory research and an artisanal pretreatment. White mulberry has a variety of chemical components, both soluble in water and solvents (Se Golpayegani, Thevenon, Grill, Masson and Pourtahmasi 
2014; Mankowski, Hassan, Bishell and Kirker, 2016, Mankowski, Boyd, Hassan and Grant, 2016) Here, timerelated water treatment seems to remove some extractives that play a significant role in dimensional stability. The longer specimens remain immersed in the water, the more extractive are taken out, and consequently wood becomes less stable when faced with extreme conditions (i.e. airdry to oven-dry).

\section{Natural durability}

\section{Towards fungi}

Results are given in table 3 and are also illustrated in figure 4. Throughout the test, both leached and unleached specimens seemed to be resistant towards the fungal attacks. The mass loss calculations were performed at the end of the test, but during the test one could observe seemingly un-colonized white mulberry blocks beside mycelia covered controls, in the same flasks. Hence, visual observation during incubation provided indications of good performance (Fig. 4).

Coniophora virulence controls had an average mass loss below $30 \%$, but one can consider that $29 \%$ average mass loss of the controls tested within the same flask as mulberry specimen allows a test validation. For all the other strains, the average mass loss of the virulence controls validated the tests. According to the requirements of XP CEN/TS 15083-1, the median mass losses of the tested samples were below $5 \%$, so the white mulberry can be classified as very durable. Among all fungi, Antrodia appears to be the most discriminatory one (Fig. 5).

The small mass losses after the attack of Poria placenta is reasonable considering that this specific fungus is usually used for softwoods (as for controls, made of pine sapwood) and would hardly make severe effects on hardwood. The median mass loss of leached specimens would still classify them as very durable (Fig. 4).

TABLE 3. Resistance of unleached and leached white mulberry against fungi attack.

\begin{tabular}{|c|c|c|c|c|c|c|c|}
\hline & \multirow[b]{4}{*}{ Fungus } & \multicolumn{6}{|c|}{ Mass loss \% } \\
\hline & & \multicolumn{4}{|c|}{ Test flasks } & \multirow{2}{*}{\multicolumn{2}{|c|}{$\begin{array}{l}\text { Virulence control } \\
\qquad n=10\end{array}$}} \\
\hline & & \multicolumn{2}{|c|}{ white mulberry } & \multicolumn{2}{|c|}{ Controls } & & \\
\hline & & $\begin{array}{l}\text { Average } \pm \\
\text { Std dev }\end{array}$ & Median & $\begin{array}{c}\text { Average } \pm \\
\text { Std dev }\end{array}$ & Median & $\begin{array}{c}\text { Average } \pm \\
\text { Std dev }\end{array}$ & Median \\
\hline \multirow[t]{6}{*}{ Unleached samples } & Coniophora puteana & $0.83 \pm 0.2$ & 0.8 & $26.7 \pm 7.7$ & 29.01 & $17.1 \pm 10.1$ & 16.9 \\
\hline & Coriolus versicolor & $1.39 \pm 0.4$ & 1.3 & $32.4 \pm 4.5$ & 33.2 & $27.2 \pm 6.8$ & 26.9 \\
\hline & Gloeophyllum trabeum & $0.9 \pm 0.3$ & 0.8 & $40.4 \pm 17.7$ & 45.2 & $46.9 \pm 16.5$ & 56.5 \\
\hline & Poria placenta & $0.6 \pm 0.2$ & 0.6 & $48.3 \pm 3.7$ & 48.0 & $37.5 \pm 3.6$ & 38.7 \\
\hline & Pycnoporus sanguineus & $1.0 \pm 0.3$ & 1.0 & $34.3 \pm 4.2$ & 33.0 & $30.6 \pm 2.6$ & 30.9 \\
\hline & Antrodia sp & $5.2 \pm 5.1$ & 3.0 & $70.0 \pm 1.1$ & 69.9 & $68.6 \pm 1.2$ & 69.2 \\
\hline \multirow[t]{6}{*}{ Leached samples } & Coniophora puteana & $0.9 \pm 0.5$ & 0.7 & $33.1 \pm 11.6$ & 31.7 & $26.9 \pm 4.2$ & 28.3 \\
\hline & Coriolus versicolor & $0.3 \pm 0.2$ & 0.3 & $35.8 \pm 7.5$ & 37.0 & $31.6 \pm 4.1$ & 32.7 \\
\hline & Gloeophyllum trabeum & $0.3 \pm 0.3$ & 0.2 & $45.5 \pm 5.4$ & 47.9 & $44.3 \pm 8.4$ & 44.9 \\
\hline & Poria placenta & $0.3 \pm 0.4$ & 0.0 & $38.2 \pm 4.6$ & 37.6 & $29.8 \pm 3.9$ & 31.1 \\
\hline & Pycnoporus sanguineus & $0.1 \pm 0.2$ & 0.1 & $31.4 \pm 3.7$ & 31.1 & $31.5 \pm 9.6$ & 31.7 \\
\hline & Antrodia sp & $16.5 \pm 7.6$ & 15.9 & $67.4 \pm 2.7$ & 68.8 & $61.8 \pm 3.5$ & 61.8 \\
\hline
\end{tabular}




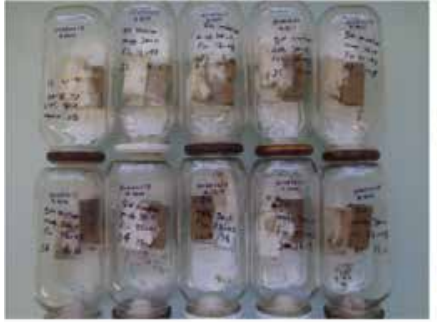

(a)

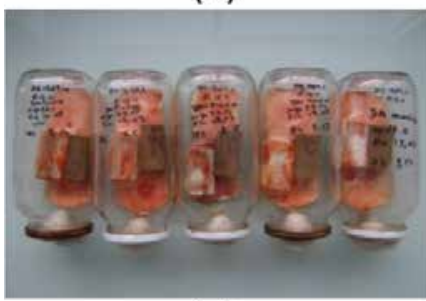

(c)

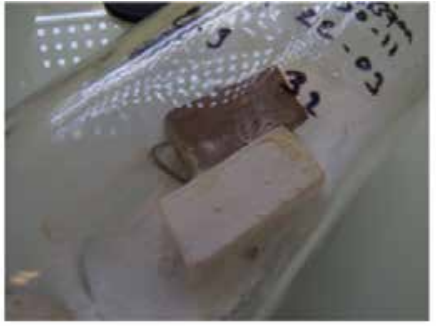

(b)

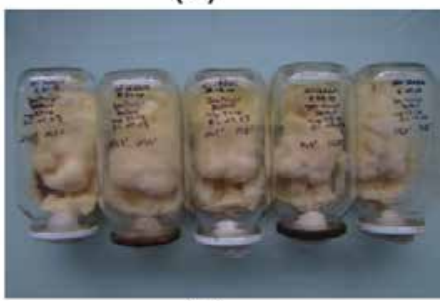

(d)
Figure 4. Specimens of white mulberry in their test flasks. $(a, b)$ : Leached white mulberry (left) beside its controls (right) attacked by Gloeophyllum trabeum. (c): Unleached white mulberry (right) and controls (left) attacked by Pycnoporus sangunesis. and (d): Controls (Scot pine) completely covered by Gloeophyllum trabeum.

This could be indication of the fact that whatever extractives the leaching could manage to remove from mulberry, had absolutely no effect on its resistance towards fungi. Considering obligatory fungi of Cen TS 15083-1, the higher median mass loss allows to classify Mulberry as very durable. On the other hand, when tested with an aggressive tropical fungus (Antrodia sp.), the removed compounds seem to play an important role in its resistance, as the durability category has changed from very durable to slightly durable.

Water leaching could not negatively affect on how the specimens reacted towards most of the fungi, which confirmed the fact that water (at least with the conditions used in this test: immersion in distilled water for 14 days in ambient temperature) could not really touch the constituents that played important roles in natural durability of white mulberry.

Having mentioned that, the case was a little bit different regarding Antrodia sp. Notwithstanding the fact that

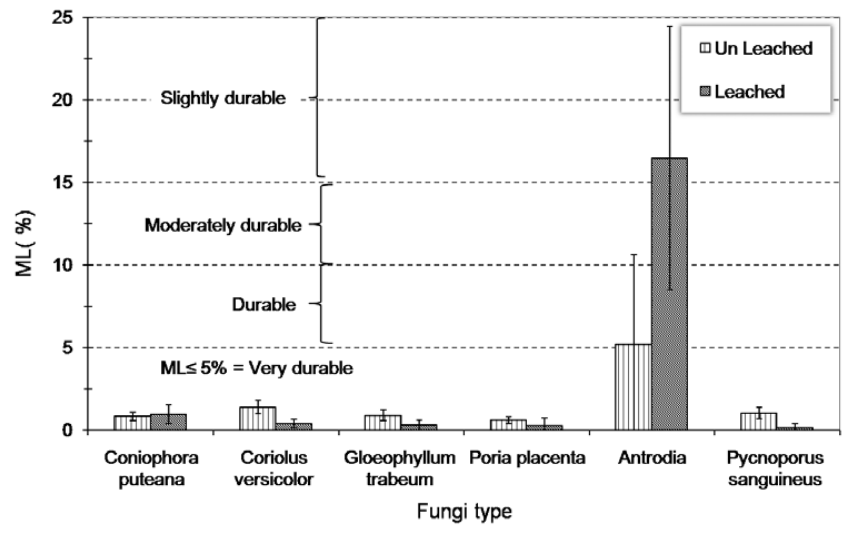

Figure 5. Comparison between mass loss of leached and unleached specimens tested against basidiomycetes. The dashed lines show the durability classifications based on XP CEN/TS 15083-1.

Antrodia sp. was used as the extreme case, it was the only fungi that its access to specimen was affected by water leaching. Morus alba contains resorcinol compounds among its extractives (Se Golpayegani et al., 2014) and Antrodia sp, strain CTFT 57A, used in this study has also demonstrated its ability to degrade timber containing resorcinol compounds extractives such as Grevillea robusta (Mburu, Dumarçay, Huber, Pretrissans and Gérardin, 2007).

\section{Termites}

The results of the durability against termites were interpreted based on mass loss and visual rating (Table 4).

The termite tests were valid and the mass loss of virulence controls was homogenous for all the samples. Like the case of fungi, mass losses of the leached samples were smaller than for the unleached ones.

The results of visual ratings on the other hand, were contradictory to the mass losses. The leached samples rated greater than unleached ones, means that visually the specimens were more consumed by the termites in the first case. Even though these results look opposing to each other, two things should be remarked: first, the observed difference between the lower bound of mass loss in unlea- 
TABLE. 4. Resistance of Morus alba specimens towards termites.

\begin{tabular}{ccccc}
\hline Samples & Worker & Visual rating & \multicolumn{2}{c}{ Mass loss \% } \\
\cline { 3 - 5 } & survival rate $\%$ & (Distribution within the samples) & Average \pm Std dev & Median \\
\hline Unleached & 0 & 1 (attempted attack) (20\% of the samples) & $2.20 \pm 0.30$ & 2.05 \\
& & 2 (slight attack) (80\% of the samples) & & \\
Leached & 0 & 3 (average attack) (100\% of the sample) & $0.91 \pm 0.33$ & 0.83 \\
Virulence controls & $>60$ & 4 (strong attack) (100\% of the sample) & $12.42 \pm 0.97$ & 12.30 \\
\hline
\end{tabular}

ched specimens ( $1.9 \%$ of dried mass) and the upper bound of leached ones $(1.24 \%$ of dried mass) is so small that raises real doubts concerning the significance of this variation between leached and unleached mulberry. Secondly, EN117 is designed to define a toxic threshold for wood preservation products, most of them being additionally designed to have a repellent effect. Thus, using the same scale for natural durability can be discussed and probably improved. Meanwhile using mass loss to interpret the results could be a more logical option.

To resume, it can be stated that white mulberry was found moderately durable towards termites, and became sensible when leached. Even though the classification according to visual rating and weigh losses were different for leached specimens; the closeness of the average observed values for leached and unleached specimens, along with their small mass losses compared to that of virulence controls $(2.20 \%$ and $0.91 \%$ compared to $12.42 \%$ in controls) makes it difficult to decide whether the obtained differences are of any real significance.

\section{DISCUSSION}

Dimensional stability and natural durability play important roles in the criteria of choosing wood for instrument making. Any tone wood is expected to hold its shape for decades (if not for centuries) for its respected instrument to be played by various musicians. Of course, for this purpose the wood should be also strong against damaging agents. This is more important in case of white mulberry for Tar, as, other than a light varnish, there is no in-process chemical treatment used to reduce the effect of possible degradation.
Water is considered an enemy and ally alike amongst artisans. On one hand, the wood should be dried to be workable and to reach a stable state. This leads to the common practice of leaving wood to be air dried for several months or even years. Water also lends a helping hand on the field of pretreatments. Being readily available, cheap and reasonably easy to manage, water remains a steady step in preparing the material for instrument making. In case of Tar, water immersion is traditionally done to remove the extractives (thus making the material easier to handle), and is believed to be helpful to the final acoustical performance.

Water removes a variety of extractives (phenols, carbohydrates, etc). Although the combination of heat and water proved to be more effective in removing chemicals (Gunduz et al., 2008; Obataya, Higashihara and Tomita, 2002; Obataya, 2010), simple soaking is also practiced and researched (Rowell, 1984; Sadler, Sharpe, Panduranga and Shivakumar, 2009). While higher temperatures are capable of removing more extractives in shorter spans of time, extending the time of treatment can sometimes match the effect of heat. Previously, it was established that in Iranian white mulberry long time water immersion and short time hot water treatment, at their most efficient state, bring out almost the same quantity of extractives (Se Golpayegani et al., 2015). These extractives play various roles in altering wood properties (Hillis, 1984; Matsunaga, Minato and Nakatsubo, 1999; Brémaud, Amusant, Minato, Grill and Thibaut, 2011; Windeisen et al. (2002); Hernandez, 2007). High amounts of extractives are reported to change shrinkage and alter 
adsorption-desorption relationship in wood (Stamm and Loughborough, 1942; Chafe, 1987). Furthermore, wood extractives contribute to the natural durability of the material (Hillis 1962 and 1978), both in their quantity (Hinterstoisser, Stefke and Schwanninger, 2000) and their inherent toxicity (Walker, 1993). However, in this study dimensional stability seemed more affected by extractives removal than natural durability. While water immersion gradually decreased the partial shrinkage, natural resistance of the white mulberry proved to be strong, whether the samples were leached or not.

\section{CONCLUSIONS}

The results of this investigation could be concluded into following points:

- Water soaking, a commonly used protocol for white mulberry wood amongst Iranian lute makers affects both natural durability and dimensional stability of the wood.

- White mulberry of Iran was classified as "very durable" towards fungi, in both leached and un leached conditions. Removal of the water soluble extractives only seems the play a role when the wood is exposed to extreme conditions with a very specific fungal strain.

- A "moderately durable" unleached white mulberry became sensible towards termites once it was water soaked. This marked termites a greater threat than fungi to the natural durability of this wood.

- Water soaking also affected the dimensional stability of the samples when the drastic change of conditions happens.

- The aforementioned result was due to the gradual removal of the extractives responsible for the stability of the wood.

To sum up, during the water soaking pretreatment some extractives would be removed. Natural durability of the wood in most of the ordinary conditions is not affected with this stage. However overall the wood becomes less stable dimension wise, and therefore should be handled more carefully.
For future, authors suggest further investigation on the dimensional stability of white mulberry and other musically important woods of Middle East (i.e. Juglans regia and Zelkova used in Santoor), using a life size instrument instead of small clear samples and exposing them to a various range of conditions in relation with their enduses and conservation.

\section{REFERENCES}

Brémaud, I., Amusant, N., Minato, K., Gril, J. and Thibaut, B. (2011). Effect of extractives on vibrational properties of African Padauk (Pterocarpus soyauxii Taub.). Wood Science and Technology, 45(3), 461-472. doi: 10.1007/ s00226-010-0337-3.

Bucur, V. (2006). Acoustics of wood. Boca Raton, USA: Springer. doi: 10.1007/3-540-30594-7.

Chafe, S. C. (1987). Collapse, volumetric shrinkage, specific gravity and extractives in Eucalyptus and other species. Wood Science and Technology, 20(4), 27-41. doi: 10.1007/BF00349715

Clausen, C. A. (2010). Wood handbook-Wood as an engineering material. (General Technical Report FPL-GTR-190). Madison, WI: U.S. Department of Agriculture, Forest Service, Forest Products Laboratory. doi: 10.2737/FPLGTR-190.

EN 117. (2013). Wood preservatives - Determination of toxic values against European Reticulitermes species (European species) (Laboratory method).

EN 84. (1997). Wood preservatives - Accelerated ageing tests of treated wood prior to biological testing - Leaching procedure.

Evans, F., Flate, P. O. and Alfredsen, G. (2008). Natural durability of different wood species in above ground, The International Research Group on Wood Protection, IRG/WP 08-10667, 14 pp. doi: 10.5552/drind.2013.1221.

Glass, S. V. and Zelinka, S. L. (2010). Moisture relation and physical properties of wood. In FPL, USDA Forest Service. Wood handbook: wood as an engineering material. Madison, WI: Forest Products Laboratory, United States Department of Agriculture Forest Service.

Gunduz, G., Korkut, S. and Korkut, D. S. (2008). The effects of heat treatment on physical and technological properties 
and surface roughness of Camiyan Black Pine (Pinus nigraArn. subsp. Pallasiana var. pallasiana) wood, Bioresource Technoly, 99(7), 2275-2280.

Haupt, M., Leithoff, H., Meier, D., Puls, J., Richter, H.G. and Faix, O. (2003). Heartwood extractives and natural durability of plantation-grown teakwood (Tectona grandis L.)-a case study. European Journal of Wood and Wood Products, 61(6), 473-474. doi: 10.1007/s00107-0030428-z.

Hernandez, R. E. (2007). Moisture sorption properties of hardwoods as affected by their extraneous substances, wood density and interlocked grain. Wood and Fiber Science, $39,132-145$

Highly, T. L. (1995). Comparative durability of untreated wood in use above ground. International Biodeterioration and Biodegradation, 35, 409-419. doi: 10.1016/09648305(95)00063-1.

Hillis, W. E. (1962). Wood Extractives and their Significance to the Pulp and Paper Industry. New York, US: Academic press.

Hillis, W. E. (1978). Extractives. Special paper, $8^{\text {th }}$ World forestry congress. Djakarta. WORLD BANK. Forestry sector policy paper. World Bank, Washington, D.C.

Hillis, W. E. (1984). High temperature and chemical effects on wood stability. Part 1: General considerations. Wood Science and Technology. 18, 281-293. doi: 10.1007/ BF00353364.

Hinterstoisser, B., Stefke, B., and Schwanninger, M. (2000). Wood: Raw material source of Energy for the future. Lignovisionen, 2, 29-36.

Li, X. J., Cai, Z. Y., Mou, Q., Wu, Y. and Liu, Y. (2011). Effects of heat treatment on some physical properties of Douglas fir (Pseudotsuga Menziesii) Wood, Advanced Materials Research, 197-198, 90-95.

Mankowski, M., Hassan, B., Bishell, A. and Kirker, G. (May 2016). Laboratory evaluations of woods from Pakistan and their extractives against Postia placenta and Trametes versicolor. Paper presented at the $47^{\text {th }}$ IRG Annual Meeting. Lisbon, Portugal.

Mankowski, M., Boyd, B., Hassan, B. and Grant T. K. G. (May 2016). GC-MS Characterizations of termiticidal heart- wood extractives from wood species utilized in Pakistan. Paper presented at the $47^{\text {th }}$ IRG Annual Meeting. Lisbon, Portugal.

Matsunaga, M., Minato, K. and Nakatsubo, F. (1999). Vibrational properties changes of spruce wood by impregnation with water soluble extractives of pernambuco (Guilandina echinata Spreng.). Journal of Wood Science, 45, 470-474. doi: 10.1007/BF00538955.

Mburu, F., Dumarçay, S., Huber, F., Petrissans, M. and Gérardin, P. (2007). Evaluation of thermally modified Grevillea robusta heartwood as an alternative to shortage of wood resource in Kenya: Characterization of physicochemical properties and improvement of bio-resistance. Bioresource Technology, 98, 3478-3486. doi:10.1016/j.biortech.2006.11.006.

Militz, H. (1993). Treatment of timber with water soluble dimethylol resins to improve their dimensional stability and durability. Wood Science and Technology, 27, 347355. doi: 10.1007/BF00192221.

Obataya, E., Higashihara, T. and Tomita, B. (2002). Hygroscopicity of heat-treated wood III: Effect of steaming on the hygroscopicity of wood. Mokuzai Gakkaishi, 48(5), 348-355.

Obataya, E. (2010). Effects of ageing and heating on the mechanical properties of wood. In L. Uzielli (Ed.). Wood science for conservation of cultural heritage. Proceeding of the International Conference COST ACTION IE0601 in Florence (pp. 16-22). Florence: Firenze University Press.

Ohmae, K., Norimoto, M. and Minato, K. (1997). Dimensional change of wood by chemical treatment. Bulletin of the Wood Research Institute, 84, 42-45.

Rowell, R. M. and Youngs, R. L. (1980). Dimensional stabilization of wood in use (Research Note FPL-0243). Oxford, England: USDA Forest Products Laboratory.

Rowell, R. M. (1984). The chemistry of solid wood. Washington D.C., US: American Chemical Society.

Rowell, R. M. and Banks, W. B. (1985). Water repellency and dimensional stability of wood (USDA Forest Service general technical report, FPL 50), Madison, Wisconsin: USDA Forest Products Laboratory.

Sadler, R. L., Sharpe, M., Panduranga, R. and Shivakumar, K. (2009). Water immersion effect on swelling and compres- 
sion properties of Eco-Core, PVC foam and balsa wood. Composite Structures, 90(3), 330-336. doi: 10.1016/j. compstruct.2009.03.016.

Sakai, K., Matsunaga, M., Minao, K. and Nakatsubo, F. (1999). Effect of impregnation of simple phenolics and natural polycyclic compounds on physical properties of wood. Journal of wood Science, 45, 227-232. doi: 10.1007/ BF01177730.

Scheffer, T. and Morrell, J. (1998). Natural durability of wood: a worldwide checklist of species. Retrieved from http:// hdl.handle.net/1957/7736

Se Golpayegani, A., Brémaud, I., Gril, J., Thévenon, M-F., Arnould, O. and Pourtahmasi, K. (2012). Effect of extractions on dynamic mechanical properties of white mulberry (Morus alba L.). Journal of wood Science, 58(2), 153-162. doi: 10.1007/s10086-011-1225-7.

Se Golpayegani, A., Thevenon, M-F., Gril, J., Masson, E. and Pourtahmasi, K. (2014). Toxicity potential in extraneous compounds of white mulberry wood. Maderas, Ciencia y tecnología, 16(2), 227-238. doi: 10.4067/S0718221X2014005000018.

Se Golpayegani, A., Brémaud, I., Gril, J., Thévenon, M-F. and Pourtahmasi, K. (2015). The effect of traditional hygrothermal pretreatments on the final acoustical characteristics of white mulberry wood (Morus alba). Maderas, Ciencia y tecnología, 17(4), 821-832. doi: 10.4067/ S0718-221X2015005000071.

Stamm, A. J. and Loughborough, W. K. (1942). Variation in shrinking and swelling of wood. Transactions of the American Society of Mechanical Engineering, 64, 379386.
Walker, J. C. F. (1993). Primary Wood Processing. Principles and Practice. London., UK: Chapman and Hall.

Wegst, U. G. K. (2006). Wood for sound. American Journal of Botany, 93(10), 1439-1448. doi: 10.3732/ajb.93.10.1439.

Wegst, U. G. K. (2008). Bamboo and wood in musical instruments. Annual Review in Materials Research, 38, 323349. doi: 10.1146/annurev.matsci.38.060407.132459.

Windeisen, E., Wegener, G. Lesnino, G. and Schumacher, P. (2002). Investigation of the correlation between extractives content and natural durability in 20 cultivated larch trees. European Journal of Wood and Wood Products, 60(5), 373-374. doi: 10.1007/s00107-002-0314-0.

XP CEN/TS 15083-1. (2006). Durability of wood and wood based products. Determination of solid wood durability against wood destroying fungi Test methods. Part 1: Basidiomycetes.

Zamir, K. (2008). Feeding preferences of Microcerotermes championi (Snyder) on different timbers dried at different temperature under choice and no choice trials. Retrieved from http://hdl.handle.net/10101/npre.2008.2048.1

Received: 9 November 2016 Accepted: 29 April 2017

This paper must be cited as:

Se Golpayegani, A., Thevenon, M.-F., Bremaud, I., Pourtahmasi, K. and Grill, J. (2017). Natural durability and dimensional stability of white mulberry (Morus alba L.) for Middle Eastern lutes. Madera y Bosques, 23(2), 193-204. doi: 10.21829/myb.2017.2321447 


\section{LIST OF SYMBOLS:}

$\tan \delta$ : Damping

$E / \rho: \quad$ Specific modulus of elasticity

L, R, T: longitudinal, radial, tangential (three orthotropic dimensions in wood)

EMC: Equilibrium moisture content

RH: Relative humidity

ML: Mass loss 